\title{
Fifty years of CPGs: two neuroethological papers that shaped the course of neuroscience
}

\author{
Brian Mulloney ${ }^{1,2} *$ and Carmen Smarandache ${ }^{1,2}$ \\ Department of Neurobiology, Physiology, and Behavior, University of California, Davis, CA, USA \\ 2 Center for Neuroscience, University of California, Davis, CA, USA
}

\section{Edited by:}

Paul S. Katz, Georgia State University, USA

\section{Reviewed by:}

Donald Edward, Georgia State

University, USA

Ronald L. Calabrese, Emory University, USA

\section{*Correspondence:}

Brian Mulloney, Department of Neurobiology, Physiology, and

Behavior, University of California, 196

Briggs Hall, One Shields Dr., Davis, CA

95616-8519, USA

e-mail: bcmulloney@ucdavis.edu
Half a century ago, two independent papers that described unexpected results of experiments on locomotion in insects and crayfish appeared almost simultaneously. Together these papers demonstrated that an animal's central nervous system (CNS) was organized to produce behaviorally important motor output without the need for constant sensory feedback. These results contradicted the established line of thought that was based on interpretations of reflexes and ablation experiments, and established that in these animals the CNS contained neural circuits that could produce complex, periodic, multisegmental patterns of activity. These papers stimulated a flowering of research on central pattern-generating mechanisms that displaced reflex-based thinking everywhere except in medical physiology texts. Here we review these papers and their influence on thinking in the 1960s, 1970s, and today. We follow the development of ideas about central organization and control of expression of motor patterns, the roles of sensory input to central pattern-generating circuits, and integration of continuous sensory signals into a periodic motor system. We also review recent work on limb coordination that provides detailed cellular explanations of observations and speculations contained in those original papers.

Keywords: motor pattern, central pattern-generation, flight, swimmeret, command neuron
Fifty years ago, two groups of zoologists working independently on the neural basis of locomotion in arthropods made similar startling observations. At Cal Tech, C. A. G. Wiersma ${ }^{1}$ and his colleague G. $M$. Hughes, visiting from Cambridge, found that the deafferented crayfish abdominal nerve cord sometimes continued to produce coordinated bursts of spikes in motor axons that innervated different swimmerets (Hughes and Wiersma, 1960), a motor pattern that drives coordinated swimmeret beating during normal forward swimming(Figure 1). They recognized that this meant the complex motor pattern that coordinated movements of four pairs of limbs (Figure 1B) could not depend on cycle-by-cycle proprioceptive feedback from the limbs themselves because they had severed all connections to those limbs.

Donald M. Wilson ${ }^{2}$, a postdoc working on locust flight in Torkel Weis-Fogh's Copenhagen laboratory, found that the detailed motor pattern that drove wing beats continued even though he had systematically severed connections from the periphery to the thoracic ganglia (Wilson, 1961). He too recognized that these behaviorally significant motor patterns were being produced by the animal's central nervous system (CNS) in the absence of cycle-by-cycle proprioceptive feedback (Edwards, 2006). These direct experimental demonstrations of complex centrally generated motor patterns

${ }^{1}$ Cornelius A. G. Wiersma (1905-1979) was Professor of Biology at California Institute of Technology. He earned his doctorate at Utrecht, joined the Cal Tech faculty in 1934, and retired in 1977.

${ }^{2}$ Donald M. Wilson (1933-1970) was Professor of Biological Sciences at Stanford, to which he moved from Berkeley following a dispute with his departmental chairman about the use of grades to determine students' military draft status. When he was 37 , he drowned in a white-water rafting accident. were startling because the then-dominant mode of thought was that proprioceptive information was essential for performance of this complexity. The rich history of research on spinal reflexes in vertebrates and the common observation of irreversible flaccid paralysis following spinal injury shaped a consensus that coordinated limb movements required cycle-by-cycle proprioceptive feedback and intact descending control from "higher centers" (Grillner, 1975, 1981; Clarac, 2008). Hughes and Wiersma (1960) and Wilson (1961) contradicted that consensus. The Discussions of both papers explicitly addressed this contradiction, and pointed out the broad significance of their results. Wilson's Discussion ends with "It seems not too early to conclude that central oscillators in arthropods are of such fundamental importance that they are used even when other mechanisms might suffice."

Wiersma and his students promptly looked more closely at the organization of the neural circuits that coordinated and controlled swimmeret movements (Ikeda and Wiersma, 1964; Wiersma and Ikeda, 1964). They compared the swimmeret motor pattern in intact animals with the patterns recorded from swimmeret nerves when the chain of six abdominal ganglia were isolated in vitro. They reported that the periods and durations of bursts of spikes in motor neurons were the same in isolated preparations and in intact animals, and that isolated preparations maintained the posteriorto-anterior progression of firing characteristic of the intact animal's movements (Figure 1B). They showed that no one ganglion served as a unique pacemaker for the system, that the intersegmental coordination pathways were bilateral, and postulated that each swimmeret had its own center that controlled its alternating powerstroke (PS) and return-stroke (RS) movements. In all respects, these 


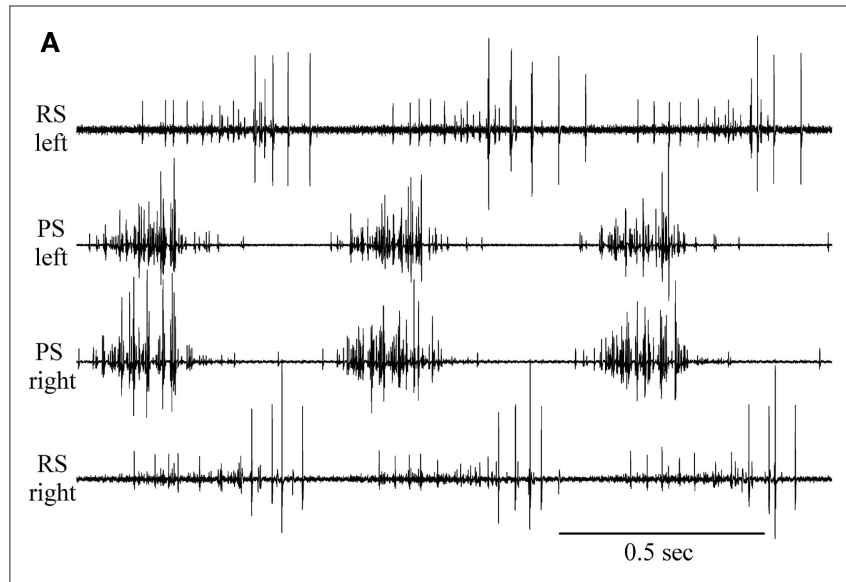

FIGURE 1 | Coordinated motor output in swimmeret motor nerves recorded from isolated abdominal nerve cords of crayfish. (A) Three cycles of motor output to the pair of swimmerets on left and right sides of one abdominal segment. Firing of axons that innervate power-stroke (PS) muscles and return-stroke (RS) muscles can be recorded from separate branches of the paired swimmeret nerve. Bursts of spikes occur simultaneously in PS axons innervating left and right swimmerets. These bursts alternate with bursts in their antagonist RS motor neurons. (B) Eight simultaneous recordings that show two cycles of firing of PS axons

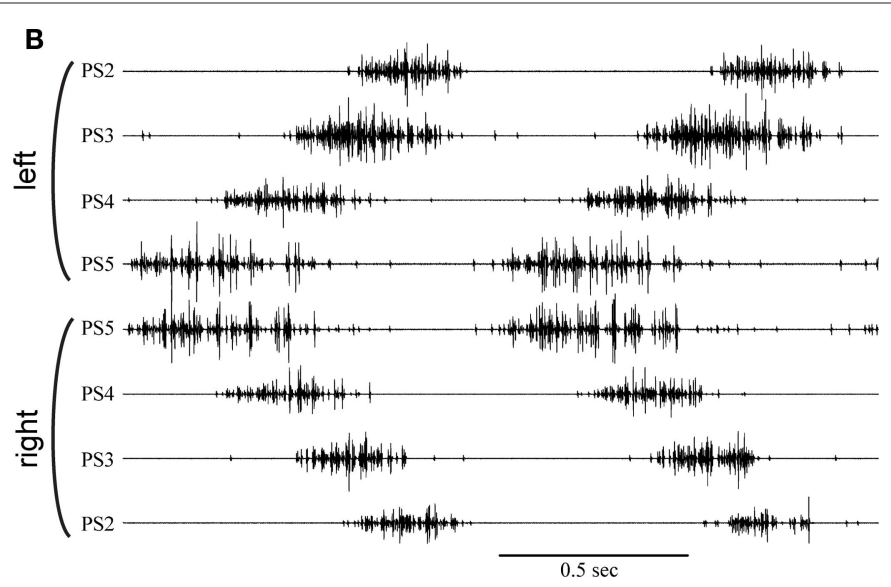

innervating four pairs of swimmerets of four segments of the abdomen. Each cycle begins with a burst of spikes in PS axons in the most posterior swimmeret ganglion (PS5). PS motor neurons in more anterior ganglia, PS4, PS3, PS2, follow in order with increasing lags. In each segment, left and right PS bursts occur simultaneously. Note: These recordings are our own work. The original figures in Hughes and Wiersma (1960) show only two traces, photographed with a 16-mm camera from the screen of a Dumont 322 oscilloscope. The totality of their observations can be grasped only by comparing multiple figures. conclusions have proven to be correct. Recent results have begun to explain how these properties emerge from the system's cellular and synaptic organization (Smarandache et al., 2009).

Wilson and Weis-Fogh (1962) described the skeletal mechanics, musculature, and motor innervation of the locust flight system, and carefully demonstrated the timing of firing in different motor units relative to wing position, wing-beat frequency, and power-output of the flight system (Wilson and Weis-Fogh, 1962). Once Wilson was established on the UC Berkeley faculty, his students continued a productive analysis of how the CNS regulated fundamental features of locust flight (Waldron, 1967). He also began a comparative investigation of flight mechanisms in other insects, including flies (Wilson and Wyman, 1963; Nachtigall and Wilson, 1967). Grasshoppers and moths are "neurogenic" fliers, whose detailed motor patterns determine each cycle of wing movements. Flies, bees, and beetles are "myogenic" fliers, whose wing movements are a resonant property of their thoracic musculo-skeletal system. Unlike the coordinated activity of locust motor neurons innervating different muscles (Figure 2), Wilson's student R. J. Wyman discovered that fly motor neurons innervating different muscles do not maintain a fixed phase relative to one another, or relative to movements of the wings. However, different neurons innervating the same muscle do maintain a fixed phase (Wyman, 1965). For one pair of muscles that are each innervated by five motor neurons, the neurons innervating each muscle fire at precisely the same frequency, but at different phases that produce a repeating sequence of spikes in the five neurons (Wyman, 1965). Thus, major features of neural control of flight were very different in these different classes of insects.

Here, we will first summarize work on four difficult questions that arose immediately from Wiersma's and Wilson's insights, and then consider how the field changed in the following decade.

\section{WHAT NEURAL MECHANISMS GENERATE THESE COMPLEX MOTOR PATTERNS?}

How, in terms of neurons and synapses, does the CNS do it? No amount of statistical analysis of the motor output could reveal the structure of the neural circuits that generated this output. The ability to record informative results from circuits within the CNS using microelectrodes was a decade in the future (Hoyle and Burrows, 1973; Pearson and Fourtner, 1975). Wilson applied what is today computational neurobiology to the problem of pattern-generating mechanisms. In an influential paper, Wilson (1966) constructed alternative models of both the locust flight controller and the fly motor neuron circuit. He used both analog and digital models to explore alternative hypotheses about the organization of the locust and fly pattern-generating circuits. He demonstrated properties of reciprocally inhibitory circuits of two, three, and four integrateand-fire neurons. In a paper published in an Engineering journal (Wilson and Waldron, 1968), he extended this analysis of the locust system and addressed differences in the stability of the output of circuits with different numbers of layers.

Turning his attention to the fly's motor patterns, Wilson (1966) proposed that the neurons that innervated each of the muscles Wyman had studied were organized by reciprocal inhibitory synapses among members of the pool. This prediction was tested by antidromic stimulation of individual motor neurons (Mulloney, 1970), which reset the sequence of firing as would be expected if the circuit of inhibitory synapses occurred among the motor neurons themselves. This result was later confirmed repeatedly and extended by Wyman's students (Levine and Wyman, 1973; Harcombe and Wyman, 1977).

Hughes and Wiersma (1960) suggested that there was a "center of coordination" for each swimmeret, and these centers were interconnected to produce the characteristic posterior-to-anterior 

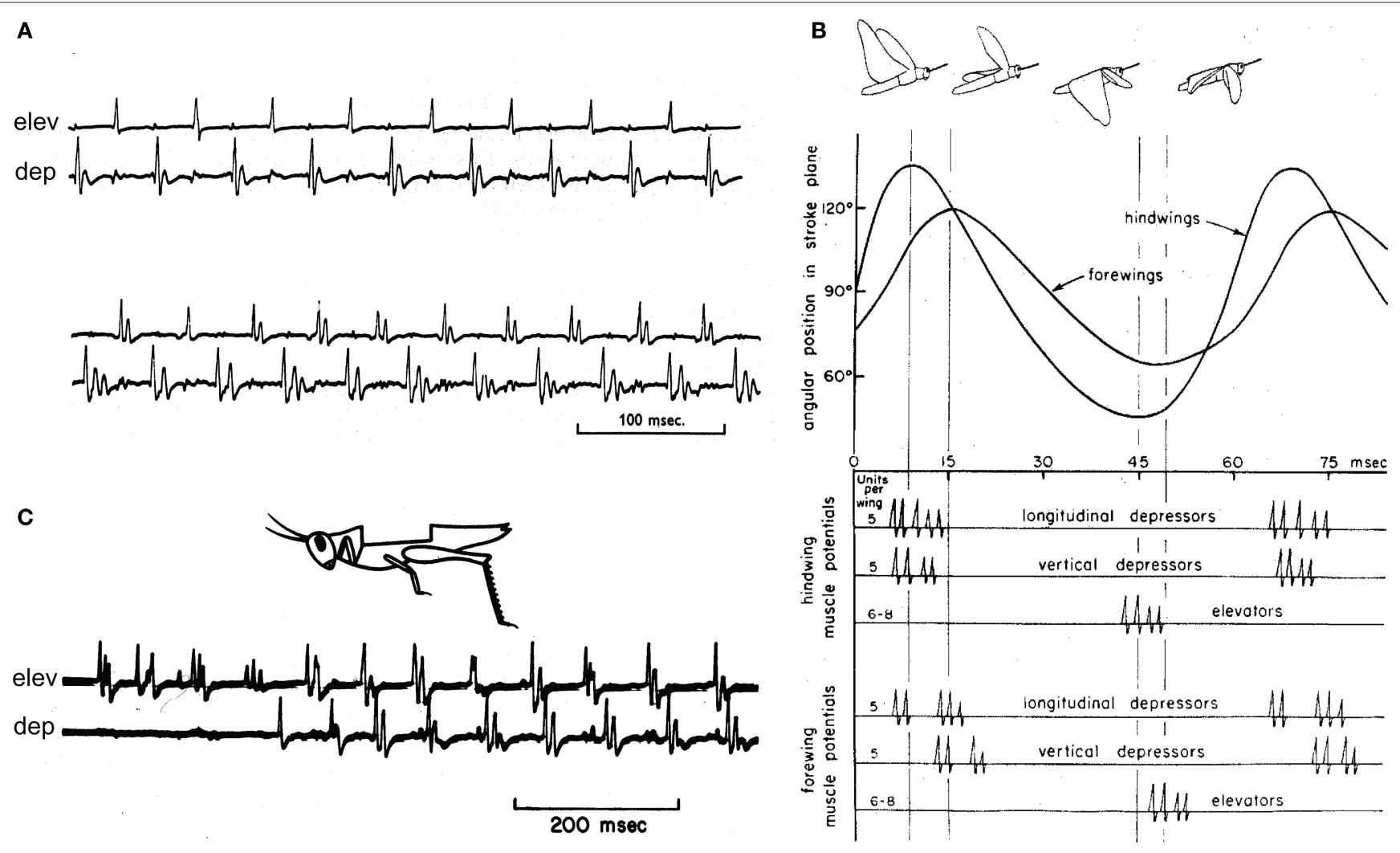

FIGURE 2 | Motor patterns that drive flight in locusts and other neurogenic insects. (A) Two sections of typical flight motor output recorded as muscle action potentials in a flying locust, from Waldron (1967). Electrodes in a wing elevator (elev) muscle and a wing depressor (dep) muscle recorded alternating spikes from these antagonistic muscles. Since transmission from the motor neurons to each muscle is one-for-one (Wilson and Weis-Fogh, 1962), these recordings report each spike in the motor neurons that innervate each muscle. These two sections of a continuous recording were separated by several seconds during which the locust increased its power-output by increasing its wing-beat frequency and increasing the numbers of spikes each neuron fired in a cycle from one to two or three spikes. (B) Wilson's diagram of the locust flight motor pattern assembled from recordings from forewing and hindwing flight muscles, plotted along with the elevation of each wing (Wilson, 1967). The cartoons of the flying locust show the wing positions at maximal elevation and depression of the fore- and hindwings. (C) Simultaneous recordings from an elevator (elev) and a depressor (dep) muscle in an locust whose wings and all wing proprioceptors had been removed (cartoon). In response to a steady wind directed toward the animal's head, the motor neurons that innervated these muscles began to fire in the characteristic flight pattern, although at a lower wing-beat frequency than would an intact locust. Reproduced from Wilson (1964) progression of PSs in each cycle. This suggestion of "centers of coordination" was borne out by later descriptions of the motor innervation of individual swimmerets. Each swimmeret is innervated by a discrete pool of motor neurons in one ganglion. The cell bodies of these neurons are located on the same side as the swimmeret they innervate, anatomically separated from the neurons innervating the swimmeret on the contralateral side (Mulloney and Hall, 2000; Mulloney et al., 2003). The non-spiking local interneurons that coordinate the neurons in each pool have unilateral structures. Their branches are restricted to the Lateral Neuropil (Skinner, 1985), near the base of the swimmeret nerve through which the motor axons project to their targets (Heitler and Pearson, 1980; Paul and Mulloney, 1985a,b). If conduction of coordinating information between Lateral Neuropils is blocked, the circuits on opposite sides of each swimmeret ganglion can continue to produce alternating oscillations of membrane potentials in functionally antagonistic neurons within one Lateral Neuropil, and these oscillations are not coordinated with activity in the opposite neuropil (Murchison et al., 1993). Thus, the two Lateral Neuropils of each swimmeret ganglion are the anatomical loci of the "centers of coordination," where alternating bursts of spikes in PS and RS motor neurons are organized by local pattern-generating circuits (Figure 3D).

\section{HOW DOES THE CNS CONTROL THESE PATTERN-GENERATING CIRCUITS?}

Hughes and Wiersma (1960) observed that stimulating small bundles of axons dissected from the interganglionic connectives had marked effects on expression of the swimmeret motor pattern. Wiersma and Ikeda (1964) mapped the locations of five pairs of axons in the connectives (out of about 2500 pairs in the whole connective) that, if stimulated with regular trains of pulses at 30-100 Hz, would elicit active expression of the swimmeret motor pattern. Stimulating each of three other pairs of axons, at different locations in the connective, would promptly inhibit the system. This was the first thorough description of command neurons, a term they introduced in the title of their paper. The idea of command neurons as neural components controlling expression of specific behaviors was appealing, and was promptly extended to 


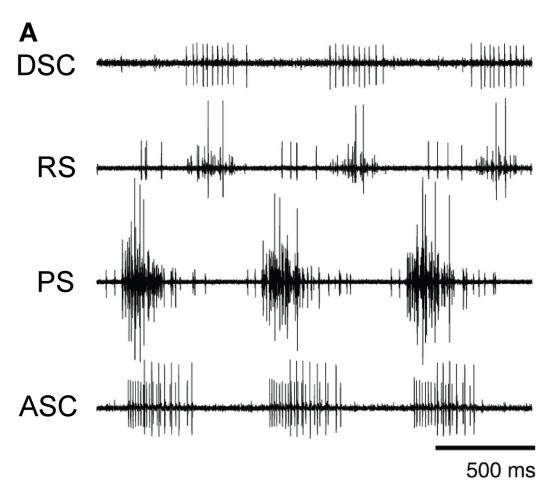

B

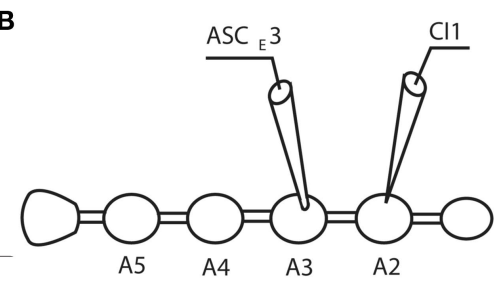

$\mathrm{ASC}_{\mathrm{E}} 3$
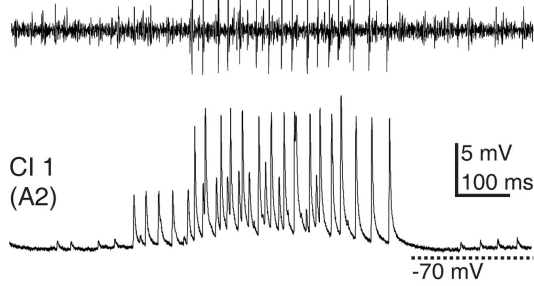

C

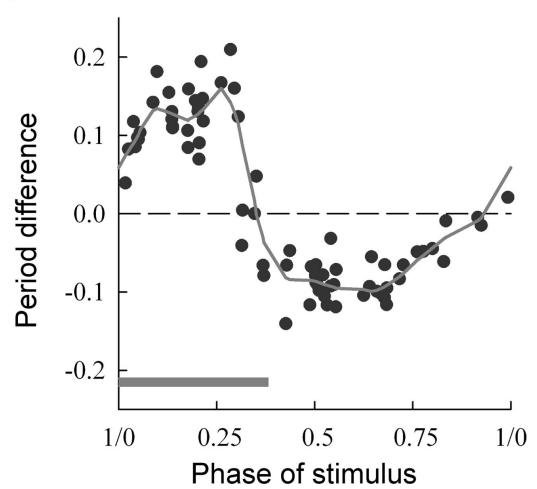

FIGURE 3 |The neural circuit that coordinates swimmeret movements.

(A) Simultaneous recordings from PS and RS branches of a nerve innervating one swimmeret and from axons of coordinating neurons that project from the local circuit that controls firing of the swimmeret's motor neurons. Bursts of spikes occur in the anterior-projecting coordinating axon (ASC) simultaneously with each PS burst. These bursts alternate with bursts in the posterior-projecting axon (DSC) that occur simultaneously with RS bursts. Each burst in ASC or DSC encodes when the corresponding burst of spikes in motor neurons began, how long it lasts, and how strong it is (Mulloney et al., 2006). (B) Simultaneous recordings of a burst of spikes in an ASC coordinating axon and the EPSPs in a Comlnt 1 commissural neuron (C1) onto which the ASC axon synapses. The cartoon shows the positions of the two recording electrodes on ganglia of the abdominal nerve cord preparation. $A 2, A 3, A 4, A 5$ : the second through fifth abdominal ganglia, each of which innervates a pair of swimmerets. (C) A phase-response curve that shows how the phase at which a pulse of depolarization in a Comlnt 1 neuron affects the period of the local circuit's
D
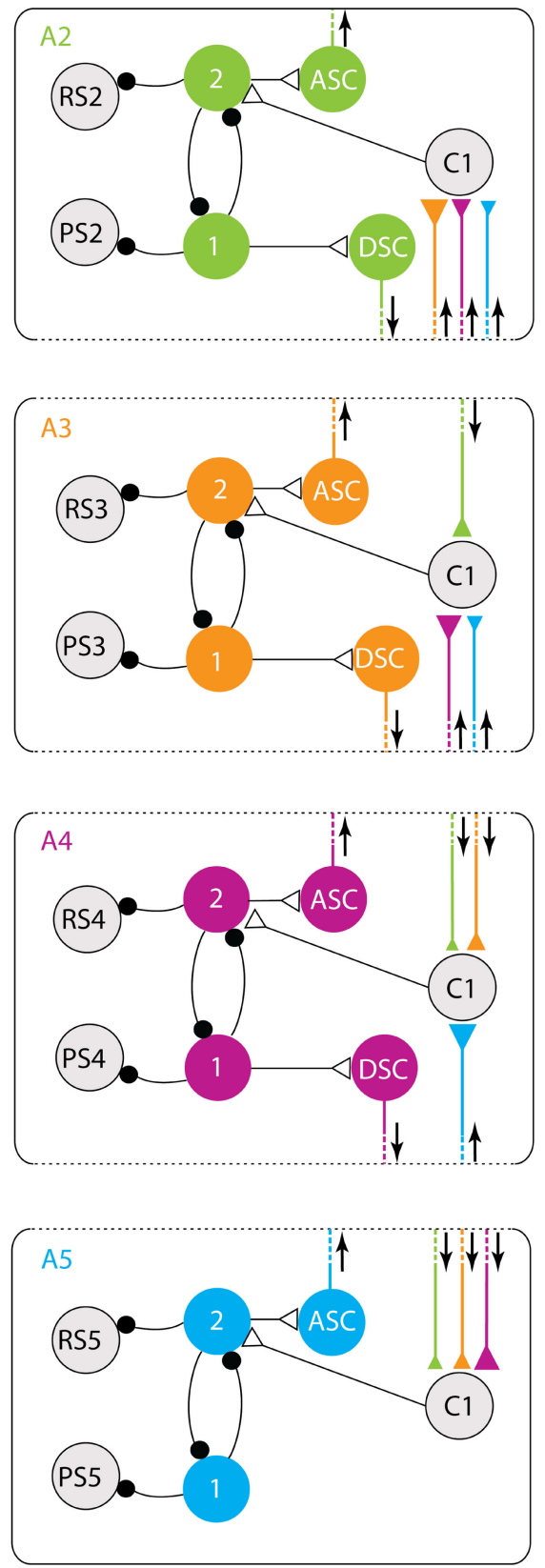

output. Here, phase is defined as the point in the cycle of PS-RS alternation at which the stimulus began. Stimuli early in a cycle, during the PS burst (gray bar), prolong the period of the cycle, but later stimuli shorten the period. The period difference is the difference between the measured period and the expected period if the stimulus had no effect. The dotted horizontal line marks zero change. The solid line is a "locally weighted estimate" fit to the data (Smarandache et al., 2009). (D) A diagram of the circuit that coordinates local pattern-generating circuits in ganglia $A 2, A 3, A 4$, and $A 5$. In each ganglion, local interneurons $(1,2)$ determine when the PS and RS motor neurons fire. In each ganglion, an $\mathrm{ASC}_{\mathrm{E}}$ and a DSC neuron encode information about the PS and RS activity and conduct it to other ganglia. This information converges onto Comlnt 1 neurons (C1) that synapse onto one of the local pattern-generating neurons. Colors mark the ganglion in which each coordinating axon originates. Triangles symbolizes excitatory synapses; larger triangles mark relatively stronger synapses. Small black circles symbolize inhibitory synapses. Arrows show the direction of impulse conduction in each coordinating axon. 
other behaviors (Atwood and Wiersma, 1967; Kennedy and Davis, 1977). In an elegant paper, Kennedy et al. (1966) performed a key control that many later authors skipped: using two extracellular electrodes, they recorded from the same axon in different segments of the body while they also recorded the motor output. With this "double-header" method, they could demonstrate that a command axon ran continuously between the two electrodes, and so was the axon of a long projection neuron, and that the effects of stimulation on the motor system appeared only if the stimulus was above that axon's threshold. Later authors neglected this control, and the term "command neuron" was sometimes applied to neurons whose anatomy and physiology clearly did not merit the term. Critics and supporters of the idea began a dialectic that continues, and has led to more restricted use of the term command neuron (Kupfermann and Weiss, 1978). Despite this controversy, Wiersma and Ikeda's original description of excitatory and inhibitory swimmeret command neurons has been confirmed and extended, and excitation by three of the five excitatory command neurons linked to the their release of a peptide neurotransmitter (Acevedo et al., 1994).

\section{HOW ARE PATTERN-GENERATING CIRCUITS LOCATED IN DIFFERENT SEGMENTS COORDINATED?}

Hughes and Wiersma (1960) also described "activity fibers" that fired busts of spikes whenever the system was actively expressing the swimmeret motor pattern. These "fibers" could be located at specific places in the interganglionic connectives, and were not axons of primary sensory afferents projecting within the CNS. Kennedy's student Paul Stein demonstrated that these axons functioned as "coordinating fibers" whose bursts of spikes originated in their home ganglion and affected the timing of PS bursts in their target ganglion(a). The influence of these bursts depended on the phase of the motor pattern at which they arrived, the phase-dependent properties that ensure entrainment and coordination of a chain of coupled oscillatory circuits (Stein, 1971, 1974). Stein's experiments were technically demanding because he had first to find and stimulate excitatory command neurons in order to locate and stimulate coordinating fibers; there was no other way known to elicit expression of the swimmeret motor pattern and with it to activate these axons. The discovery that the neuropeptide proctolin and the cholinergic agonist carbachol would reliably elicit expression in isolated ventral nerve cord preparations (Mulloney et al., 1987; Braun and Mulloney, 1993; Chrachri and Neil, 1993) enabled additional analysis of mechanisms of swimmeret coordination.

The characteristic coordination of local circuits that control different swimmerets requires information encoded in each circuit by two intersegmental projection neurons (Stein, 1971; Namba and Mulloney, 1999). The axon of one neuron projects anteriorly to targets in more anterior ganglia, and fires a burst of spikes simultaneously with each burst in PS motor neurons in their home ganglion (Figure 3A). The axon of the second neuron projects posteriorly to targets in more posterior ganglia, and fires a burst of spikes simultaneously with each burst in RS motor neurons (Tschuluun et al., 2001). Using dye-filled microelectrodes to record from and to stimulate individual coordinating neurons in their home ganglion while the system was actively generating the swimmeret motor pattern allowed us to describe their structures, to confirm their coordinating capabilities by constructing more detailed phase-response curves, and to demonstrate the correlation of the numbers of spikes in each burst with the timing, duration, and strengths of simultaneous bursts in motor neurons (Mulloney et al., 2006; Mulloney and Hall, 2007). So, Hughes and Wiersma's (1960) suggestions that the system included local "centers of coordination" that are interconnected to produce effective limb movements was correct.

How do these coordinating axons achieve this performance? Since in the swimming animal the different swimmerets are synchronized to the same period, their local pattern-generating circuits can be considered a chain of coupled oscillators (Kopell and Ermentrout, 1988). Skinner et al. (1997) applied formal coupled oscillator theory to the swimmeret system, and described fundamental features that ascending and descending coordinating information must have in order to synchronize different oscillators so they have the same period and the same posterior-to-anterior phase progression like that of the swimmerets. To tie these theoretical results together with the newly identified coordinating neurons (Namba and Mulloney, 1999), Skinner and Mulloney (1998b) constructed a cellular model of the local pattern-generating circuit, and constructed a series of alternative models of the coordinating circuit that couples a chain of these local circuits together. These models were interesting because they were restricted by physiological and anatomical knowledge of the system, and just one of the alternative models performed as did the system itself. That model maintained a posterior-to-anterior phase progression despite changes in the period of the system's oscillations like those caused by changes in excitation of the real system. Thus, that model could be viewed as a prediction of the cellular organization of the swimmeret system. Jones et al. then used tools from coupled oscillator theory to explain why a coordinating circuit like this could preserve stable phase differences in the face of large changes in period (Jones et al., 2003; Jones and Kopell, 2006). This series of computational models not only illuminated how Hughes and Wiersma's "activity fibers" could enable stable intersegmental phase differences, but also how the ascending and descending "coupling-functions" of coupled oscillator theory could be embodied in the bursts of spikes in specific coordinating axons (Skinner and Mulloney, 1998a).

In each ganglion to which they project, each of these coordinating axons synapses onto a commissural neuron, ComInt 1 (Mulloney and Hall, 2003), that integrates the information that they transmit and affects the timing and strength of one local circuit's motor output (Mulloney and Hall, 2007). Because of the different phases at which ascending and descending coordinating neurons in each local circuit fire and the phase lag between segments (Figure 3), bursts of spikes in ascending and descending axons from neighboring ganglia arrive simultaneously at each ComInt 1 (Mulloney and Hall, 2003). These synapses onto ComInt 1 are excitatory, and their excitatory postsynaptic potentials (EPSPs) are quite brief (Smarandache et al., 2009). The effects of depolarizing pulses injected into a ComInt 1 neuron depend on the phase at which the pulse occurs; pulses that occur early in the cycle delay the next PS burst, but pulses that occur later in the cycle advance the next PS burst (Figure 3C). Thus, bursts of spikes in coordinating axons from different segments converge onto ComInt 1 neurons that integrate the EPSPs these spikes cause, transmit this information to local pattern-generating circuits, and so entrain these 
circuits to the same period. We think that the systematic differences in strengths of synapses in this coordinating circuit (Smarandache et al., 2009), combined with differences in the numbers of spikes per burst in coordinating axons from different segments (Mulloney et al., 2006), are the basis for the posterior-to-anterior progression of PS bursts (Figure 1B).

\section{IF CPGS CAN PRODUCE THE EFFECTIVE MOTOR PATTERNS NEEDED FOR MOST BEHAVIORS, WHY DO ANIMALS HAVE SO MANY PROPRIOCEPTIVE REFLEXES?}

The discovery that many behaviors in many kinds of animals were driven by centrally generated motor patterns, and that sensory reflexes were gated by these central circuits led many students of the time to dismiss the contributions of reflexive information to natural behaviors. Wilson himself fell into this error for a while, but then realized the mistake. In a paper remarkable both for experimental design and clarity of thought (Wilson, 1968), he demonstrated two independent factors that could make a motor pattern maladaptive: individual developmental asymmetries and unpredictable environmental or life-history events. Using flying locusts free to roll about their anterior-posterior axis, he showed experimentally that if an animal could detect the maladaptive behavior these factors caused, it would promptly modify its motor output to correct the error. He showed that proprioceptive information, vision from both ocelli and compound eyes, and windreceptors on the head could each contribute to effective flight, that the flight system could continue effectively if any single sensory component was eliminated, and that the system failed only gradually as these sources of information were progressively eliminated one-by-one (Wilson, 1968).

The first understanding of how the locust CNS integrated exteroceptive information to tune the flight motor output followed Martin Wilson's description of the optics of locust ocelli and their detection of pitch and roll about the animal's major body axes (Wilson, 1977).A remarkable study used microelectrodes in flying preparations (Robertson and Pearson, 1982) to record integration of activity in descending ocellar interneurons (Rowell and Reichert, 1986) by the local thoracic flight CPGs. This ocellar activity is inherently aperiodic, but to tune the motor output to correct for pitch or roll required that it affect elevator and depressor motor neurons at different phases in the flight pattern (Figure 2B). Reichert and Rowell $(1985,1986)$ demonstrated that the aperiodic descending input makes EPSPs with these motor neurons that must sum with periodic excitation from the local CPG in order to cause firing in the postsynaptic neuron. This periodic excitation from the CPG reaches antagonistic motor neurons at different phases in each cycle, so the descending signals can affect the strengths of motor output without disrupting phase coordination of antagonistic motor neurons.

\section{THE IMPACT OF THIS WORK ON OUR CONCEPTS OF THE NEURAL BASIS OF NATURAL BEHAVIORS}

There was at first a natural tendency to think of CPGs as a feature limited to arthropod locomotion in fluid media - air and water. Then, experimental deafferentation of whole limbs in newts (Szekely et al., 1969), vocal apparatus in birds (Murphey and
Phillips, 1967), thoracic ganglia in cockroaches (Pearson, 1972), and segmental ganglia in leech (Kristan Jr. and Calabrese, 1976) all yielded evidence that CPGs were at work driving swimming, walking, breathing, and calling in most animals (Delcomyn, 1980). Within the decade, Wilson's conclusion had begun to shape experimental questions and design even in leading mammalian physiology laboratories. Fictive locomotion from isolated spinal cord of lamprey was a critical result because it demonstrated unequivocally the capacities of spinal CPGs (Cohen and Wallén, 1980). Pearson and Rossignol's meticulous demonstration of fictive locomotion in spinal cats challenged the last holdouts for mammalian exceptionalism (Pearson and Rossignol 1991), and forced new clinical approaches to treating spinal injuries.

With the realization that CPGs were widespread came the need to discover how they were structured. Concerted efforts to identify pattern-generating neurons and their synaptic organization - the neural circuits that generated specific motor patterns - often encountered technical and biological obstacles. The comprehensive descriptions of the lobster stomatogastric circuitry (Mulloney and Selverston, 1974a,b; Selverston and Mulloney, 1974; Maynard and Selverston, 1975; Mulloney, 1977; Eisen and Marder, 1982) and the swimming circuit in leech (Friesen et al., 1976) exploited particularly favorable preparations where we could record synaptic interactions among key neurons in preparations that were actively expressing the behaviorally significant motor patterns. This link to overt behavior that distinguish Hughes and Wiersma (1960) and Wilson (1961) remains key to progress in discovering the organization of neural circuits of all kinds, and understanding the neural basis of natural behaviors.

It is a remarkable commentary on the influence of social factors on acceptance of scientific results that the existence of CPGs in the mammalian spinal cord had been well demonstrated 50 years before (Graham Brown, 1911), and essentially ignored by received opinion. In 1960, a magisterial review in the Handbook of Physiology (Denny-Brown, 1960) made no mention of Graham Brown's papers on locomotion. His papers began to be read again and recognized in the renaissance that followed Wilson (1961). Stuart and Hultborn (2008) recount the resurrection from obscurity of Graham Brown's work and ideas by Lundberg (1969), as the new perspective on pattern-generation and motor control took hold.

Neuroscience as a discipline has often advanced because of technical innovations, but less commonly because of theoretical achievements. Contemporary research takes as a starting point that central neural circuits can produce essential patterned activity, not only in motor systems (Grillner, 2006; Marder and Bucher, 2007) but even in mammalian cortex (Yuste et al., 2005). The insights in Hughes and Wiersma (1960) and Wilson (1961) are one of those less common contributions where skillful experiments and astute interpretation changed the ways we think about what nervous systems do and how they are organized.

\section{ACKNOWLEDGMENTS}

We thank W. M. Hall and C. Weller for reading the manuscript critically, and assisting in preparing figures. Our research is supported by NIH grant NS04-8068 and NSF grant 0905063. 


\section{REFERENCES}

Acevedo, L. D., Hall, W. M., and Mulloney, B. (1994). Proctolin and excitation of the crayfish swimmeret system. $J$. Comp. Neurol. 345, 612-627.

Atwood, H. L., and Wiersma, C. A. G. (1967). Command interneurons in the crayfish central neurons system. J. Exp. Biol. 46, 249-261.

Braun, G., and Mulloney, B. (1993). Cholinergic modulation of the swimmeret system in crayfish. $J$. Neurophysiol. 70, 2391-2398.

Chrachri, A., and Neil, D. M. (1993). Interaction and synchronization between two abdominal motor systems in crayfish. J. Neurophysiol. 69, 1373-1383.

Clarac, F. (2008). Some historical reflections on the neural control of locomotion. Brain Res. Rev. 57, 13-21.

Cohen, A. H., and Wallén, P. (1980). The neuronal correlate of locomotion in fish: "fictive swimming" induced in an in vitro preparation of the lamprey spinal cord. Exp. Brain Res. 41, $11-18$.

Delcomyn, F. (1980). Neural basis of rhythmic behavior in animals. Science 210, 492-498.

Denny-Brown, D. (1960). "Motor mechanisms - introduction: the general principles of motor integration," in Handbook of Physiology, Section 1: Neurophysiology, Vol. II, eds J. Field, H. W. Magoun, and V. E. Hall (Bethesda, MD:American Physiological Society) 1067-1088.

Edwards, J. S. (2006). The central nervous control of insect flight. J. Exp. Biol. 209, 4411-4413.

Eisen, J. S., and Marder, E. (1982). Mechanisms underlying pattern generation in lobster stomatogastric ganglion as determined by selective inactivation of identified neurons. III. Synaptic connections of electrically coupled pyloric neurons. $J$. Neurophysiol. 48, 1392-1415.

Friesen, W. O., Poon, M., and Stent, G. S. (1976). An oscillatory neuronal circuit generating a locomotory rhythm. Proc. Natl. Acad. Sci. U.S.A. 73, 3734-3738.

Graham Brown, T. (1911). The intrinsic factors in the act of progression in mammals. Proc. R. Soc. Lond., B, Biol. Sci. 84, 308-319.

Grillner, S. (1975). Locomotion in vertebrates: central mechanisms and reflex interaction. Physiol. Rev. 55, 247-304.

Grillner, S. (1981). "Control of locomotion in bipeds, tetrapods and fish," in Handbook of Physiology, the Nervous System, Vol. 2, Motor Control, ed. V. B. Brooks (Baltimore, MD: Williams and Wilkins), 1179-1236.
Grillner, S. (2006). Biological pattern generation: the cellular and computational logic of networks in motion. Neuron 52, 751-766.

Harcombe, E. S., and Wyman, R. J. (1977). Output pattern generation by Drosophila flight motoneurons. J. Neurophysiol. 40, 1066-1077.

Heitler, W. J., and Pearson, K. G. (1980) Non-spiking interactions and local interneurones in the central pattern generator of the crayfish swimmeret system. Brain Res. 187, 206-211.

Hoyle, G., and Burrows, M. (1973). Neural mechanisms underlying behavior in the locust Schistocerca gregaria: I. Physiology of identified motoneurons in the metathoracic ganglion. J. Neurobiol. 4, 3-42.

Hughes, G. M., and Wiersma, C. A. G. (1960). The co-ordination of swimmeret movements in the crayfish, Procambarus clarkii. J. Exp. Biol. 37, 657-670.

Ikeda, K., and Wiersma, C. A. G. (1964). Autogenic rhythmicity in the abdominal ganglion of the crayfish: the control of swimmeret movements. Comp. Biochem. Physiol. 12, 107-115.

Jones, S. R., and Kopell, N. (2006). Local network parameters can affect internetwork phase lags in central pattern generators. J. Math. Biol. 52, 115-140.

Jones, S. R., Mulloney, B., Kaper, T. J., and Kopell, N. (2003). Coordination of cellular pattern-generating circuits that control limb movements: the sources of stable differences in intersegmental phase. J. Neurosci. 23, 3457-3468.

Kennedy, D., and Davis, W. J. (1977) "Organization of invertebrate motor systems," in Handbook of Physiology. Section 1: The Nervous System, Vol. 1, Part 2, Cellular Biology of Neurons, ed. E. R. Kandel (Bethesda, MD: American Physiological Society), 1023-1088.

Kennedy, D., Evoy, W. H., and Hanawalt, J. T. (1966). Release of coordinated behavior in crayfish by single central neurons. Science 154, 917-919.

Kopell, N., and Ermentrout, G. B. (1988). Coupled oscillators and the design of central pattern generators. Math. Biosci. 90, 87-109.

Kristan, W. B. Jr., and Calabrese, R. L. (1976). Rhythmic swimming activity in neurons of the isolated nerve cord of the leech. J. Exp. Biol. 65, 643-668.

Kupfermann, I., and Weiss, K. R. (1978) The command neuron concept. Behav. Brain Sci. 1, 3-39.

Levine, J. D., and Wyman, R. J. (1973). Neurophysiology of flight in wild-type and a mutant Drosophila. Proc. Natl. Acad. Sci. U.S.A. 70, 1050-1054.

Lundberg, A. (1969). Reflex Control of Stepping. Nansen Memorial Lecture.
Oslo: Norwegian Academy of Sciences.

Marder, E., and Bucher, D. (2007). Understanding circuit dynamics using the stomatogastric nervous system of lobsters and crabs. Annu. Rev. Physiol. 69, 291-316.

Maynard, D. M., and Selverston, A. I. (1975). Organization of the stomatogastric ganglion of the spiny lobster IV. The pyloric system. J. Comp. Physiol. A Neuroethol. Sens. Neural. Behav. Physiol. 100, 161-182.

Mulloney, B. (1970). Organization of flight motoneurons of Diptera. J. Neurophysiol. 33, 86-95.

Mulloney, B. (1977). Organization of the stomatogastric ganglion of the spiny lobster. V. Coordination of the gastric and pyloric systems. J. Comp. Physiol. A Neuroethol. Sens. Neural. Behav. Physiol. 122, 227-240.

Mulloney, B., Acevedo, L. D., and Bradbury, A. G. (1987). Modulation of the crayfish swimmeret rhythm by octopamine and the neuropeptide proctolin. J. Neurophysiol. 58 584-597.

Mulloney, B., and Hall, W. M. (2000). Functional organization of crayfish abdominal ganglia: III. Swimmeret motor neurons. J. Comp. Neurol. 419 , 233-243.

Mulloney, B., and Hall, W. M. (2003) Local commissural interneurons integrate information from intersegmental coordinating interneurons. $J$. Comp. Neurol. 466, 366-476.

Mulloney, B., and Hall, W. M. (2007) Local and intersegmental interactions of coordinating neurons and local circuits in the swimmeret system. $J$. Neurophysiol. 98, 405-413.

Mulloney, B., Harness, P. I., and Hall, W M. (2006). Bursts of information: coordinating interneurons encode multiple parameters of a periodic motor pattern. J. Neurophysiol. 95 , 850-861.

Mulloney, B., and Selverston, A. I. (1974a) Organization of the stomatogastric ganglion of the spiny lobster. I. Neurons driving the lateral teeth. J. Comp. Physiol. A Neuroethol. Sens. Neural. Behav. Physiol. 91, 1-32.

Mulloney, B., and Selverston, A. I. (1974b) Organization of the stomatogastric ganglion of the spiny lobster. III. Coordination of the two subsets of the gastric systems. J. Comp. Physiol. A Neuroethol. Sens. Neural. Behav. Physiol. 91, 53-78.

Mulloney, B., Tschuluun, N., and Hall, W. M. (2003). Architectonics of crayfish ganglia. Microsc. Res. Tech. 60 253-265.

Murchison, D., Chrachri, A., and Mulloney, B. (1993). A separate local pattern-generating circuit controls the movements of each swimmeret in crayfish. J. Neurophysiol. 70, 2620-2631.

Murphey, R. K., and Phillips, R. E. (1967). Central patterning of a vocalization in fowl. Nature 216, 1125-1126.

Nachtigall, W., and Wilson, D. M. (1967). Neuromuscular control of dipteran flight. J. Exp. Biol. 47, 77-97.

Namba, H., and Mulloney, B. (1999). Coordination of limb movements: three types of intersegmental interneurons in the swimmeret system, and their responses to changes in excitation. J. Neurophysiol. 81, 2437-2450.

Paul, D. H., and Mulloney, B. (1985a). Local interneurons in the swimmeret system of the crayfish. J. Comp. Physiol A Neuroethol. Sens. Neural. Behav. Physiol. 156, 489-502.

Paul, D. H., and Mulloney, B. (1985b). Nonspiking local interneuron in the motor pattern generator for the crayfish swimmeret. J. Neurophysiol. $54,28-39$.

Pearson, K. G. (1972). Central programming and reflex control of walking in the cockroach. J. Exp. Biol. 56, 173-193.

Pearson, K. G., and Fourtner, C. R. (1975). Nonspiking interneurons in walking system of the cockroach. $J$. Neurophysiol. 38, 33-52.

Pearson, K. G., and Rossignol, S. (1991). Fictive motor patterns in chronic spinal cats. J. Neurophysiol. 66, 1874-1887.

Reichert, H., and Rowell, C. H. F. (1985) Integration of nonphaselocked exteroceptive information in the control of rhythmic flight in the locust. $J$. Neurophysiol. 53, 1201-1218.

Reichert, H., and Rowell, C. H. F. (1986) Neuronal circuits controlling flight in the locust: how sensory information is processed for motor control. Trends Neurosci. 9, 281-283.

Robertson, R. M., and Pearson, K. G. (1982). A preparation for the intracellular analysis of neuronal activity during flight in the locust. J. Comp. Physiol. A Neuroethol. Sens. Neural. Behav. Physiol. 146, 311-320.

Rowell, C. H. F., and Reichert, H. (1986) Three descending interneurons reporting deviation from course in the locust. II. Physiology. J. Comp. Physiol. A Neuroethol. Sens. Neural. Behav. Physiol. 158, 775-794.

Selverston, A. I., and Mulloney, B. (1974) Organization of the stomatogastric ganglion of the spiny lobster. II. Neurons driving the medial tooth. J. Comp. Physiol. A Neuroethol. Sens. Neural. Behav. Physiol. 91, 33-51.

Skinner, F. K., Kopell, N., and Mulloney, B. (1997). How does the crayfish swimmeret system work? Insights from nearest neighbor coupled oscillator models. J. Comput. Neurosci. 4, 151-160. 
Skinner, F. K., and Mulloney, B. (1998a). Intersegmental coordination in invertebrates and vertebrates. Curr. Opin. Neurobiol. 8, 725-732.

Skinner, F. K., and Mulloney, B. (1998b). Intersegmental coordination of limb movements during locomotion: mathematical models predict circuits that drive swimmeret beating. J. Neurosci. 18, 3831-3842.

Skinner, K. (1985). The structure of the fourth abdominal ganglion of the crayfish, Procambarus clarkii. II. Synaptic neuropils. J. Comp. Neurol. 234, 182-191.

Smarandache, C. R., Hall, W. M., and Mulloney, B. (2009). Coordination of rhythmic motor activity by gradients of synaptic strength in a neural circuit that couples modular neural oscillators. J. Neurosci. 29, 9351-9360.

Stein, P. S. G. (1971). Intersegmental coordination of swimmeret motor neuron activity in crayfish.J. Neurophysiol.34, 310-318.

Stein, P. S. G. (1974). Neural control of interappendage phase during locomotion. Am. Zool. 14, 1003-1016.

Stuart, D. G., and Hultborn, H. (2008). Thomas Graham Brown (1882-1965),
Anders Lundberg (1920-), and the neural control of stepping. Brain Res. Rev. 59, 74-95.

Szekely, G., Czeh, G., and Voros, G. y. (1969). The activity pattern of limb muscles in freely moving normal and deafferented newts. Exp. Brain Res. 9, 53-62.

Tschuluun, N., Hall, W.M., and Mulloney, B. (2001). Limb movements during locomotion: tests of a model of an intersegmental coordinating circuit. J. Neurosci. 21, 7859-7869.

Waldron, I. (1967). Neural mechanism by which controlling inputs influence motor output in the flying locusts. $J$. Exp. Biol. 47, 213-228.

Wiersma, C. A. G., and Ikeda, K. (1964). Interneurons commanding swimmeret movements in the crayfish, Procambarus clarkii. Comp. Biochem. Physiol. 12, 509-525.

Wilson, D.M.(1961). The central nervous control of flight in a locust. J. Exp. Biol. 38, 471-490.

Wilson, D. M. (1964) "The origin of the flight-motor command in grasshoppers," in Neural Theory and Modeling, ed. R. F. Reiss (Palo Alto: Stanford University Press), 331-345.
Wilson, D. M. (1966). Central nervous mechanisms for the generation of rhythmic behavior in arthropods. Symp. Soc. Exp. Biol. 20, 199-228.

Wilson, D.M. (1967). The nervous control of insect flight and related behavior. Adv. Insect Physiol. 5, 289-338.

Wilson, D. M. (1968). Inherent asymmetry and reflex modulation of thelocust flight motor pattern. J. Exp. Biol. 48, 631-641.

Wilson, D. M., and Waldron, I. (1968). Models for the generation of the motor output pattern in flying locust. Proc. IEEE 56, 1058-1064.

Wilson, D. M., and Weis-Fogh, T. (1962). Patterned activity of coordinated motor units, studied in flying locusts. J. Exp. Biol. 39, 643-667.

Wilson, D. M., and Wyman, R. J. (1963). Phasically unpatterned nervous control of dipteran flight. J. Insect Physiol. 9, 859-865.

Wilson, M. (1977). The functional organization of locust ocelli. J. Comp. Physiol. A Neuroethol. Sens. Neural. Behav. Physiol. 124, 297-316.

Wyman, R. J. (1965). Probabalistic characterization of simultaneous nerve impulse sequences controlling dipteran flight. Biophys. J. 5, 447-471.
Yuste, R., MacLean, J. N., Smith, J., and Lansner, A. (2005). The cortex as a central pattern generator. Nat. Rev. Neurosci. 6, 477-483.

Conflict of Interest Statement: The authors declare that the research was conducted in the absence of any commercial or financial relationships that could be construed as a potential conflict of interest.

Received: 07 April 2010; paper pending published: 20 April 2010; accepted: 29 June 2010; published online: 19 July 2010.

Citation: Mulloney B and Smarandache C (2010) Fifty years of CPGs: two neuroethological papers that shaped the course of neuroscience. Front. Behav. Neurosci. 4:45. doi: 10.3389/fnbeh.2010.00045

Copyright (c) 2010 Mulloney and Smarandache. This is an open-access article subject to an exclusive license agreement between the authors and the Frontiers Research Foundation, which permits unrestricted use, distribution, and reproduction in any medium, provided the original authors and source are credited. 